\title{
Intermittent Suckling Causes a Transient Increase in Cortisol That Does Not Appear to Compromise Selected Measures of Piglet Welfare and Stress ${ }^{\dagger}$
}

\author{
Diana L. Turpin ${ }^{1, *}$, Pieter Langendijk ${ }^{2, \ddagger}$, Tai-Yuan Chen ${ }^{2}$, David Lines ${ }^{3}$ and John R. Pluske ${ }^{1}$ \\ 1 School of Veterinary and Life Sciences, Murdoch University, Murdoch WA 6150, Australia; \\ J.Pluske@murdoch.edu.au \\ 2 South Australian Research and Development Institute, Roseworthy Campus, JS Davis Building, \\ Roseworthy SA 5371, Australia; Pieter.Langendijk@trouwnutrition.com (P.L.); Tai.Chen@sa.gov.au (T.-Y.C.) \\ 3 Sunpork Farms, Wasleys SA 5400, Australia; dlines@austporkfarms.com.au \\ * Correspondence: D.Turpin@murdoch.edu.au; Tel.: +61-411-795-020 \\ $\dagger \quad$ Aspects of this work have been published as: Turpin, D.; Langendijk, P.; Chen, T-Y.; Lines, D.; Pluske, J.R. \\ Intermittent suckling causes a stress response in piglets that is attenuated over time. Anim. Prod. Sci. 2015, \\ 55,1480 . \\ $\ddagger$ Current address: Trouw Nutrition, Veerstraat 38, Boxmeer $5831 \mathrm{JN}$, The Netherlands.
}

Academic Editor: Clive J. C. Phillips

Received: 29 January 2016; Accepted: 14 March 2016; Published: 17 March 2016

Simple Summary: This study assessed the effects intermittent suckling (IS) had on physiological and behavioral indices of piglets before and after weaning. Piglets were allocated to either a control treatment (conventional weaning) or an IS treatment (separation from the sow for $8 \mathrm{~h}$ per day starting the week before weaning). Apart from an initial peak in cortisol at the start of IS, piglets subjected to IS did not show physiological changes suggestive of a chronic stress response before and after weaning. The event of weaning still caused a decrease in growth rate and an increase in white blood cell parameters in both treatment groups. However, the IS piglets tended to gain more weight in the second half of the week after weaning. The results of this study suggest that short periods of separation (e.g., $8 \mathrm{~h} /$ day) do not appear to compromise piglet welfare over the peri-weaning period.

\begin{abstract}
This study tested the hypothesis that piglets subjected to intermittent suckling (IS) would show changes in physiological and behavioral indices indicative of compromised welfare in the peri-weaning period. A total of 21 primiparous sows and their litters were allocated to either a control treatment $(n=10)$ where piglets were weaned conventionally, or an IS treatment $(n=11)$ where piglets were separated daily from their sows for $8 \mathrm{~h}$ starting the week before weaning. Performance, physiological and behavioral measures were taken at various time points during the week before and after weaning. Plasma cortisol levels were higher $(p=0.01)$ in IS piglets $7 \mathrm{~d}$ before weaning. Regardless of treatment, the N:L ratio at $3 \mathrm{~d}$ and $7 \mathrm{~d}$ after weaning was higher $(p<0.05)$ than that at $1 \mathrm{~d}$ before weaning. The IS piglets ate more creep feed during lactation $(p<0.05)$, and there was a tendency for the IS piglets to gain more weight between $3 \mathrm{~d}$ and $7 \mathrm{~d}$ after weaning $(p<0.1)$. This study showed that, aside from an increase in cortisol at the start of IS, piglets subjected to IS did not display physiological or behavioral changes indicative of compromised welfare.
\end{abstract}

Keywords: pig; weaning; intermittent suckling; welfare; stress

\section{Introduction}

The induction of estrus and subsequent mating during lactation is an alternative reproduction system that is being explored by some pork industries around the world to reduce sow confinement. 
In this system, anestrus, which is usually experienced by the sow in lactation, is primarily overcome by the use of a limited nursing weaning regime such as intermittent suckling (IS) [1] in combination with boar exposure [2]. Intermittent suckling involves a temporary daily separation of the piglets from the sow during the latter part of lactation to reduce the suppressive effect that suckling has on luteinizing hormone secretion, which may allow ovulation to occur and subsequent conception during lactation [1]. Since one of the main stressors a piglet experiences under commercial conditions is weaning [3], IS regimes appear to have the benefit of mimicking the increasing amount of time sows would spend away from their piglets under more natural conditions, which has been shown to provide benefits to piglets after weaning [4,5]. Temporarily separating piglets from the sow before weaning allows piglets to become more familiar with solid food as an alternative nutrient source to milk, which causes increased solid feed intake before weaning and a subsequent improvement in growth after weaning [6-9]. However, the act of repeated maternal separation during lactation on aspects of the piglets' stress response is of potential welfare concern since it is well established that maternal separation experienced at weaning is associated with altered behavior patterns such as aggression, belly nosing and higher vocalization rates [10], and a transient increase in adrenocorticotrophic hormone and cortisol most likely resulting from emotional stress of the mother-infant separation and exposure to a new environment [11]. Therefore, it is important to establish that short, repeated periods of separation during lactation do not make the event of weaning even more stressful.

The hypothesis tested in this study was that piglets separated from their dam for $8 \mathrm{~h}$ per day for $7 \mathrm{~d}$ in the week before weaning would show physiological and behavioral indices indicative of compromised welfare in the peri-weaning period. The study also examined the proposition that post-weaning performance would be superior in pigs subjected to IS before weaning compared with piglets from a conventional weaning regime due to increased creep feed intake.

\section{Materials and Methods}

The experimental design and procedures were approved by the Animal Ethics Committees of Primary Industries and Resources South Australia (25/13) and Murdoch University (N2650/14).

\subsection{Animals, Experimental Design, Diets and Housing}

The experiment was conducted on a commercial pig farm in South Australia. One block of 25 first-parity sows (Large White $x$ Landrace) and their offspring were used. The number of piglets born alive varied from nine to thirteen with an average litter size of $10.3 \pm 1.6$ (mean $\pm \mathrm{SD}$ ). One sow was replaced with a foster sow due to poor udder development and three other sows were excluded from the trial due to low litter size, leaving a total of 21 sows and 216 piglets for use in the study.

At farrowing, sows and their litters were randomly allocated to one of two treatments: conventional weaning (CW) (control group) $(n=10 \mathrm{~L})$ or intermittent suckling (IS) $(n=11 \mathrm{~L})$. In total, 104 piglets were part of the CW treatment group and 112 piglets were part of the IS treatment group. The piglets in the CW treatment group remained with their sow continuously through the lactation period until weaning. The piglets in the IS treatment were separated from their sow and housed in a separation pen (see description below) for $8 \mathrm{~h}$ per day (07:00-15:00) for $7 \mathrm{~d}$ before weaning (average age at the start of separation was $22 \pm 1.3 \mathrm{~d}$; mean \pm SD). Separation was achieved by ushering the piglets through an open gate between the crate and the separation pen. This process involved minimal handling and once the piglets had been moved, the gate was kept closed.

During lactation, the sows and piglets were housed in conventional farrowing pens $(1.7 \mathrm{~m} \times 2.4 \mathrm{~m})$. The pens consisted of a covered, heated creep area for the piglets and a crate to individually house the sows $(0.6 \mathrm{~m} \times 2.4 \mathrm{~m})$ while still allowing piglet access. A sow feeder and nipple drinker were located at the front of the crate. At the rear of each pen was a larger pen $(1.7 \mathrm{~m} \times 2 \mathrm{~m})$ separated by a gate. This area was used to house the piglets during separation and was called the separation pen. Both the farrowing pen and separation pen had plastic, slatted flooring. Within $24 \mathrm{~h}$ of farrowing, piglets received a $1 \mathrm{~mL}$ IM iron injection (Feron 200+B12, $200 \mathrm{mg} / \mathrm{mL}$ iron dextran and 
$40 \mathrm{ug} / \mathrm{mL}$ cyanocobalamin; Bayer Healthcare, Pymble, Australia), a 2 mL IM injection of RespiSure $\mathrm{One}^{\circledR}$ (Mycoplasma hyopneumoniae vaccine; Pfizer, West Ryde, Australia), and their tails were cut and cauterized. Sows were fed a standard lactation $\operatorname{diet}(9.14 \mathrm{MJ} \mathrm{NE} / \mathrm{kg} ; \mathrm{CP}, 170 \mathrm{~g} / \mathrm{kg}$; standardised ileal digestible (SID) lysine, $8.7 \mathrm{~g} / \mathrm{kg}$ ) at $2.5 \mathrm{~kg}$ per day until and including the day of farrowing and then were fed ad libitum from the day after farrowing until weaning. All piglets were offered creep feed (9.6 MJ NE/kg; CP, $220 \mathrm{~g} / \mathrm{kg}$; crude fibre (CF), $34 \mathrm{~g} / \mathrm{kg}$; SID lysine, $13.3 \mathrm{~g} / \mathrm{kg}$ ) ad libitum from a rotary feeder with hopper (one feeder per farrowing crate) from $14 \mathrm{~d}$ before weaning. When piglets were separated from the sow, the rotary feeder with the creep feed was moved into the separation pen. An additional rotary feeder was used to supply water in the separation pen.

The average weaning age for both the control (CW) and IS treatment groups was $29.1 \pm 1.8 \mathrm{~d}$ (mean $\pm \mathrm{SD}$ ). The piglets were transported a short distance from the farrowing building to the weaner building and sorted according to treatment, sex and size. There were eight weaner pens $(1.7 \mathrm{~m} \times 3.4 \mathrm{~m})$ in total with an average of $24.8 \pm 2.1$ pigs per pen. The pens were divided into IS and CW treatment groups with small and large males and small and large females. Half of the pen floor was concrete with sawdust and the other half was slatted plastic. There was a nipple drinker at the back of the pen and a 5-hole weaner hopper on the side allowing pigs to have ad libitum access to weaner feed (9.6 MJ NE/ kg; $\mathrm{CP}, 197 \mathrm{~g} / \mathrm{kg}$; CF, $40 \mathrm{~g} / \mathrm{kg}$; SID lysine, $11.4 \mathrm{~g} / \mathrm{kg}$ ). Gas heaters fitted to the roof were used to heat the room. At this time, pigs received an oral dose of Enterisol ${ }^{\circledR}$ Ileitis (Boehringer Ingelheim, St Joseph, MO, USA) and $1 \mathrm{~mL}$ IM CircoFLEX ${ }^{\circledR}$ (porcine Circovirus associated disease vaccine; Boehringer Ingleheim Vetmedica, Berkshire, UK, RG128YS).

\subsection{Measurements}

Fourteen days before weaning, eight piglets per litter were made individually identifiable with numbered ear tags. Individual identification was used to trace litter groups and to monitor which piglets had been used for blood sampling (see details below). All piglets were weighed individually at $14 \mathrm{~d}, 7 \mathrm{~d}$ and $4 \mathrm{~d}$ before weaning and on the day of weaning. At $3 \mathrm{~d}$ and $7 \mathrm{~d}$ after weaning, a subsample of approximately 1-12 ear tagged pigs per weaner pen were randomly selected and individually weighed. Within the randomly selected subsample of pigs that were weighed after weaning, it was also ensured that four pigs per original litter group were represented. Creep feed disappearance from each feeder was measured on $7 \mathrm{~d}$ and $4 \mathrm{~d}$ before weaning, on the day of weaning and $3 \mathrm{~d}$ and $7 \mathrm{~d}$ after weaning. Creep feed that had disappeared from the feeder was considered eaten (there was little to no wastage).

An injury score, a subjective estimate of aggression, was collected from six randomly selected pigs per pen the day after weaning. The injury scoring system was adapted from Widowski et al. [12] and consisted of a four point scale for scratches and redness around the heads, ears, abdomen and flank. The injury score was assessed while the selected pigs were being weighed.

\subsection{Blood and Plasma Analyses}

At $7 \mathrm{~d}, 4 \mathrm{~d}$ and $1 \mathrm{~d}$ before weaning and $1 \mathrm{~d}, 3 \mathrm{~d}$ and $7 \mathrm{~d}$ after weaning, two piglets were randomly selected per litter and a blood sample was collected (piglets were not bled more than 2 times within a 7 day period). Blood sampling started at noon and it took approximately $2 \mathrm{~h}$ to sample 42 piglets. Therefore, for the days before weaning, sampling took place approximately $4 \mathrm{~h}$ to $6 \mathrm{~h}$ after separation of the IS piglets from the sow. Piglets were held in dorsal recumbency and blood samples were collected via jugular venipuncture with the procedure lasting no more than 90 seconds. The samples were collected in a lithium heparin coated tube and an EDTA coated tube. The EDTA samples were kept refrigerated overnight at $4{ }^{\circ} \mathrm{C}$ and the lithium heparin samples were centrifuged on the day of collection $\left(20 \mathrm{~min}\right.$ at $2800 \times \mathrm{g}$ at $\left.4{ }^{\circ} \mathrm{C}\right)$, and then $1 \mathrm{ml}$ of plasma aliquots were stored at $-80^{\circ} \mathrm{C}$.

Plasma cortisol and corticotrophin releasing hormone (CRH) were determined using commercially available ELISA kits (Enzo Life Sciences, Cortisol ELISA kit, AD-901-071, Farmingdale, NY and BioSource Porcine Corticotrophin Releasing Hormone ELISA kit, MBS267253, San Diego, CA, USA) in 
accordance with the manufacturers' instruction with the exception of the optical density for cortisol, which was read at $415 \mathrm{~nm}$ instead of the recommended $405 \mathrm{~nm}$. The intra-assay CV for cortisol was $10.5 \%$ (low), $6.6 \%$ (medium) and $7.3 \%$ (high), and $\leqslant 8 \%$ for CRH.

White blood cell differential counts were measured electronically using a Cell Dyn 3700 (Abbotts, Macquarie Park, Australia). Plasma was analyzed at Animal Health Laboratories (Department of Agriculture and Food Western Australia) for the determination of haptoglobin.

\subsection{Statistical Methods}

Statistical analysis was performed using SPSS (v.21; IBM, St Leonards, Australia). All data were tested for normality using the Shapiro-Wilk value ( $>0.80$ was considered normally distributed). The litter was the experimental unit for average daily feed intake (ADFI) before weaning as well as average daily gain (ADG) and body weight (BW) before and after weaning. The pen was the experimental unit for ADFI after weaning. To calculate the ADG from weaning to $3 \mathrm{~d}$ after weaning, the average BW of the litter at weaning was subtracted from the average BW of the four pigs representing the litter $3 \mathrm{~d}$ after weaning. This value was then divided by three to account for the $3 \mathrm{~d}$ difference between the measurements. Values for ADFI before weaning, cortisol and N:L ratios were negatively skewed, requiring transformation to force normality using $\log _{10}$ transformation before analysis. The mean values and confidence intervals were then back-transformed and expressed as least square means with 95\% confidence intervals. Values for BW, ADG, ADFI and injury scores were analyzed using a general linear model with treatment as the fixed effect. Body weights at $14 \mathrm{~d}$ before weaning were also included as a covariate for the post-weaning BW and ADG analysis. A linear mixed model was used to analyze cortisol, N:L ratios, CRH and haptoglobin levels with sow identification and pen (after weaning only) fitted as random effects, and treatment and day as fixed effects. A day by treatment interaction was then used. Correlations involving ADFI were performed using the Pearson correlation test. Statistical significance was accepted at $p<0.05$, and a trend was considered at $p \leqslant 0.1$ and $p \geqslant 0.05$.

\section{Results}

\subsection{Piglet Mortality}

Piglet pre-weaning mortality (from $14 \mathrm{~d}$ of the experiment to weaning) was $7.7 \%$ for $\mathrm{CW}$ piglets compared with $2.7 \%$ for IS piglets, however this difference was not significant $(p>0.1)$. There was no difference in post-weaning mortality (one week after weaning) between treatments ( $4.2 \%$ for $\mathrm{CW} v \mathrm{v}$. $4.6 \%$ for IS, $p=1.00)$.

\subsection{Blood Measures Indicative of Stress and Welfare, and Injury Scores}

The IS treatment group had the highest cortisol concentration $7 \mathrm{~d}$ before weaning (the first day of separation) (Figure $1 ; p<0.001$ ), but this effect disappeared $6 \mathrm{~d}$ later. There was no treatment or day effect for cortisol concentration on $1 \mathrm{~d}$ and $7 \mathrm{~d}$ after weaning (Figure $1 ; p>0.05$ ). There was no difference in $\mathrm{CRH}$ concentration between the treatment groups at $7 \mathrm{~d}$ and $1 \mathrm{~d}$ before weaning (Figure 1; $p>0.05)$. However, one day after weaning, the IS group exhibited a reduction in CRH concentration resulting in a concentration that was lower than that of the CW pigs (Figure $1 ; p<0.01$ ). Seven days after weaning, the CRH concentration of the IS group increased again back to a similar concentration as the $\mathrm{CW}$ group (Figure $1 ; p>0.05$ ). 


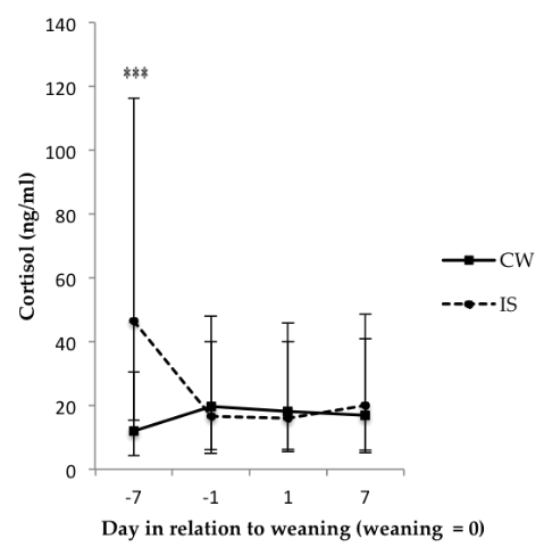

(a)

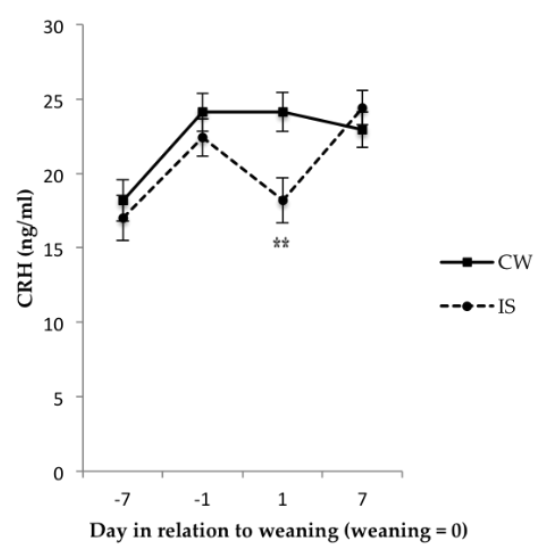

(b)

Figure 1. Effect of intermittent suckling (IS) on plasma (a) cortisol and (b) corticotropin releasing hormone $(\mathrm{CRH})$ of piglets before and after weaning. ${ }^{* *}$ Indicates differences between treatments $(p<0.01)$ per sampling day; ${ }^{* *}$ indicates differences between treatments $(p<0.001) ; n=20$ for conventional weaning (CW) and $n=22$ for IS. Plasma cortisol data were logarithmically transformed and then back transformed and expressed as least square means with $95 \%$ confidence intervals.

The CW litters tended to have a higher $\mathrm{N}: \mathrm{L}$ ratio at $7 \mathrm{~d}$ before weaning compared with the IS litters (Figure 2; $p=0.1$ ). There was no significant treatment effect for $\mathrm{N}: \mathrm{L}$ ratio for the other time points up to $7 \mathrm{~d}$ after weaning. When treatments were combined, the $\mathrm{N}: \mathrm{L}$ ratio on $3 \mathrm{~d}$ and $7 \mathrm{~d}$ after weaning was greater $(p<0.05)$ than the $\mathrm{N}: \mathrm{L}$ ratio $1 \mathrm{~d}$ before weaning.

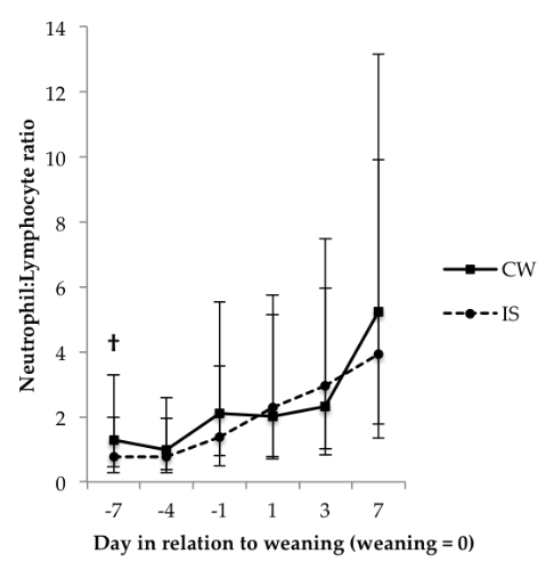

(a)

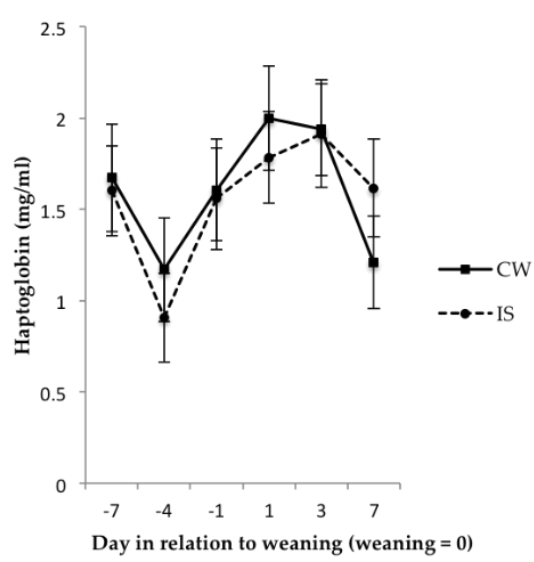

(b)

Figure 2. Effects of IS on plasma (a) N:L ratio and (b) haptoglobin of piglets before and after weaning. t Indicates trends between treatments $(p<0.1$ ) per sampling day; $n=20$ for $\mathrm{CW}$ and $n=22$ for IS. Data for N:L ratios were were logarithmically transformed and then back transformed and expressed as least square means with $95 \%$ confidence intervals.

There was no difference in haptoglobin between treatments for any of the time points measured (Figure $2 ; p>0.05$ ). However, there was an overall day effect for haptoglobin with values at $4 \mathrm{~d}$ before weaning being lower $(p<0.05)$ than values on other measurement days except $7 \mathrm{~d}$ after weaning $(p>0.05)$. There was no significant treatment effect for incidence of scratches on the skin the day after weaning, with the scores being $2.0 \pm 0.18$ for CW vs. $2.3 \pm 0.17$ for IS (mean \pm SD; $p>0.05$ ). This was the same for redness measured on the same day; $0.70 \pm 0.16$ for CW vs. $0.96 \pm 0.16$ for IS (mean \pm SD; $p>0.05)$. 


\subsection{Production Measures}

There was no difference in piglet BW between the two treatment groups in the period from $14 \mathrm{~d}$ before weaning to $7 \mathrm{~d}$ after weaning (Table $1 ; p>0.05)$. Piglet ADG did not differ $(p>0.05)$ between $\mathrm{CW}$ and IS litters before the start of IS, and there was also no treatment effect for ADG during the week of IS ( $7 \mathrm{~d}$ before weaning to weaning) (Table $2 ; p>0.05$ ). In the period from weaning to $3 \mathrm{~d}$ after weaning, both treatment groups exhibited a dramatic decrease in ADG, but there was no treatment effect (Table $2 ; p>0.05$ ). From $3 \mathrm{~d}$ to $7 \mathrm{~d}$ after weaning, IS pigs tended to have a higher ADG than the CW pigs (Table $2 ; p<0.1$ ).

Table 1. Mean piglet body weight $(\mathrm{kg}) 14$ days before weaning to $7 \mathrm{~d}$ after weaning for two different weaning regimens.

\begin{tabular}{ccccc}
\hline Day $^{\mathbf{1}}$ & \multicolumn{2}{c}{ Weaning Regimen $^{2}$} & SEM & $p$-Value \\
\hline & CW & IS & & \\
-14 & 4.8 & 4.5 & 0.26 & 0.42 \\
-7 & 6.4 & 6.0 & 0.34 & 0.44 \\
-4 & 7.0 & 6.5 & 0.38 & 0.33 \\
0 & 8.2 & 7.4 & 0.45 & 0.22 \\
3 & 8.2 & 7.3 & 0.23 & 0.23 \\
7 & 8.7 & 8.1 & 0.26 & 0.93
\end{tabular}

${ }^{1}$ Day in relation to weaning with 0 representing weaning (e.g., -14 is $14 \mathrm{~d}$ before weaning); ${ }^{2} \mathrm{CW}$, conventional weaning; $(n=9)$; IS, intermittent suckling starting at day $21(n=11)$.

Table 2. Average daily gain (ADG) (grams per piglet) before and after weaning and average daily feed intake (ADFI) (grams per piglet) before weaning in two different weaning regimens.

\begin{tabular}{|c|c|c|c|c|}
\hline \multirow{2}{*}{ Item } & \multicolumn{2}{|c|}{ Weaning Regimen $^{1}$} & \multirow{2}{*}{ SEM } & \multirow{2}{*}{$p$-Value } \\
\hline & $\mathrm{CW}$ & IS & & \\
\hline \multicolumn{5}{|l|}{ ADG (g) } \\
\hline \multicolumn{5}{|l|}{ Before weaning } \\
\hline Day $-14^{2}$ to day -7 & 223 & 222 & 14.8 & 0.63 \\
\hline Day -7 to day -4 & 210 & 184 & 31.4 & 0.38 \\
\hline Day -4 to weaning & 281 & 212 & 38.9 & 0.20 \\
\hline \multicolumn{5}{|l|}{ After weaning } \\
\hline Weaning to day $3^{3}$ & 2 & -26 & 43.1 & 0.63 \\
\hline Day 3 to day $7^{3}$ & 134 & 209 & 28.7 & 0.07 \\
\hline \multicolumn{5}{|l|}{$\operatorname{ADFI}(g)^{4}$} \\
\hline Day -14 to day -7 & $6(3.81-10.59)$ & $8(4.85-12.22)$ & & 0.57 \\
\hline Day -7 to day -4 & $14(7.24-26.42)$ & $42(22.54-77.09)$ & & 0.02 \\
\hline Day -4 to weaning & $25(12.30-50.12)$ & $57(30.27-106.41)$ & & 0.08 \\
\hline
\end{tabular}

Before the start of IS, there was no difference in the ADFI of creep feed between the two treatment groups (Table $2 ; p>0.05$ ). However, after the start of IS, creep ADFI was higher in IS litters in the period between $7 \mathrm{~d}$ and $4 \mathrm{~d}$ before weaning $(p<0.05)$ and tended to be higher in IS litters in the period from $4 \mathrm{~d}$ before weaning to weaning $(p<0.1)$ (Table 2). Average total creep feed intake during lactation was $291 \pm 138.7 \mathrm{~g} /$ piglet (mean $\pm \mathrm{SD}$ ) for CW and $679 \pm 125.4 \mathrm{~g} /$ piglet for IS $(p=0.05)$. However, creep ADFI was variable between the litters of different sows during lactation with total disappearance during lactation ranging from $98 \mathrm{~g} /$ piglet to $851 \mathrm{~g} /$ piglet in the CW litters, and $185 \mathrm{~g} /$ piglet to 
$1848 \mathrm{~g} /$ piglet in the IS litters. There was no treatment effect for ADFI when IS and CW pens were compared in the $7 \mathrm{~d}$ after weaning ( $147 \pm 9.4 \mathrm{~g} /$ piglet/day for CW vs. $143 \pm 9.4 \mathrm{~g} /$ piglet/day for IS; $p>0.05)$.

During lactation, there was a strong correlation between creep ADFI for the period 7 to 4 days before weaning and ADFI for the period from $4 \mathrm{~d}$ before weaning to weaning $(r=0.87 ; p<0.001)$. However, no significant correlations existed between ADFI and ADG during the same time period. On the other hand, there was a positive correlation between ADFI during the entire lactation period and ADG between $3 \mathrm{~d}$ and $7 \mathrm{~d}$ after weaning $(r=0.47 ; p<0.05)$.

\section{Discussion}

Intermittent suckling is a form of gradual weaning that can induce an estrus during lactation [13,14], allowing transfer of the mating management to the farrowing room and potentially reducing sow confinement after weaning. Previously, IS weaning regimes have shown improvements in the adaptation of piglets to weaning, and therefore arguably an improvement to welfare, through an increase in creep feed intake before weaning leading to an improvement in post-weaning performance $[6,7,9]$. However, there is concern that repeated maternal separation at a young age in lactation can cause emotional stress, compromising piglet welfare.

Plasma cortisol and CRH were used as physiological indicators of stress in the current study. However, and as defined by Moberg [15], stress is a biological response mechanism elicited when an individual perceives a threat to its homeostasis. When investigating the possible effects that IS has on piglet welfare, it is important to be able to identify when an animal is unable to physiologically or behaviorally cope with the challenge [15], i.e., when there is a biological cost to the animal [16]. In the current study, there was an elevation in plasma cortisol after the first $4 \mathrm{~h}$ to $6 \mathrm{~h}$ of separation for the IS piglets compared to the CW piglets. This is consistent with previous studies that have looked at maternal separation in piglets $[17,18]$ and other species [19], however it seems the IS piglets adapted to separation as cortisol values returned to the level of CW piglets by $6 \mathrm{~d}$. To the authors' knowledge, no other studies looking at IS have measured physiological stress responses during the separation period, however a behavior study by Berkeveld et al. [20] showed an increase in total litter activity in the IS piglets on the first day of separation, but this effect disappeared by the next measurement $2 \mathrm{~d}$ later. Despite the increase in activity reported by Berkeveld et al. [20], manipulative and aggressive behaviors associated with piglet distress in the same study were absent in IS litters during the separation period, but control litters experienced an increase in belly-nosing immediately after weaning. Although detailed behavior measurements were not taken in the current study, it seems that an increase in cortisol occurred at the same time (on the first day of separation) as the increased level of activity in the study by Berkeveld et al. [20], and in that study, the increase in activity was not associated with behaviors indicative of distress. In the current study, no differences between treatments were observed during the IS period with respect to growth, plasma $\mathrm{CRH}$, blood N:L ratios and plasma haptoglobin levels. Therefore, it appears that IS piglets were able to adapt to the previously inexperienced separation from the sow with no overall biological cost to the animal suggesting that welfare, at least under the measures used in this study, was not compromised.

There was no day or treatment effect for cortisol after weaning when comparing values for the day before weaning to values for the period of $1 \mathrm{~d}$ and $7 \mathrm{~d}$ after weaning. The lack of a day effect is contrary to some weaning studies where an elevation in plasma, urinary or salivary cortisol was seen the day of or the day after weaning [21-24]. This lack of treatment effect in cortisol after weaning could be explained by the lack of difference in aggression between the groups after weaning as evidenced by the injury score results. Worsaae and Schmidt [25] showed that plasma cortisol concentrations in pigs can be positively correlated to post-weaning aggression, but since pigs in the current study were weaned at 29 days, they were perhaps less likely to develop behavior patterns associated with reduced welfare [26]. 
Similarly, there was also no day or treatment effect for haptoglobin over the weaning transition from $1 \mathrm{~d}$ before weaning to $7 \mathrm{~d}$ after weaning with all values sitting below the acute range of $3000 \mathrm{ug} / \mathrm{mL}$ to $8000 \mathrm{ug} / \mathrm{mL}$ [27]. The reason for the decrease in haptoglobin values at $4 \mathrm{~d}$ before weaning is not known. Haptoglobin is a major acute phase protein in the pig whose concentration in serum can vary in response to injury, infection, inflammation or stress [28,29]. Acute stress of less than $4 \mathrm{~h}$ is ineffective at altering haptoglobin levels [30]; however, an increase in haptoglobin can be seen $1 \mathrm{~d}$ to $3 \mathrm{~d}$ after an infectious insult [31-33]. Studies that measure the haptoglobin in response to weaning-related stressors which do not necessarily lead to health problems have shown an increase in haptoglobin at $7 \mathrm{~d}$ [34] and $10 \mathrm{~d}$ [35] after weaning compared to the day of weaning. This response was not seen in the current study, which suggests a lack of inflammatory response over the immediate post-weaning period, or it could also reflect the previously reported high level of variation in haptoglobin levels in apparently healthy pigs [27,36,37].

Despite no increase in cortisol or haptoglobin concentrations after weaning for both treatments, the increase in N:L ratios at $3 \mathrm{~d}$ and $7 \mathrm{~d}$ after weaning (when treatments were combined) in parallel to decreased ADG suggests that weaning was a stressful event. The immunological reactions that the stress of weaning can induce in pigs has been well documented [38-41], with studies also showing an increase in N:L ratio in the immediate post-weaning period [42,43]. However, the absence of a significant treatment effect in N:L ratios for all the time points after weaning suggests that exposure to IS before weaning does not have any further negative impact on the post-weaning immune response, as assessed by the N:L ratio.

Psychological stress has been linked to gastrointestinal tract dysfunction (GIT) [44,45]. In a study by Moeser et al. [24], the intestinal permeability of 19-day-old weaned piglets was increased compared with age-matched unweaned piglets, with the expression of corticotropin releasing hormone (CRH) receptors found to be increased in the intestinal tissue of the weaned pigs. In the same study, serum CRH levels seemed to reflect GIT disturbances more so than cortisol, suggesting that CRH may be a more sensitive indicator for stress induced intestinal dysfunction. The CRH results in the present study are not consistent with results from Moeser et al. [24] where weaning induced significant increases in serum CRH compared with unweaned controls. This lack of consistency may be an issue of weaning age since it seems this elevation in CRH over weaning is more pronounced at younger weaning ages ( $15 \mathrm{~d}$ to $19 \mathrm{~d}$ ) than older ages ( $23 \mathrm{~d}$ to $28 \mathrm{~d}$ ) [41,46]. It is interesting, however, that CRH concentrations in the current study are generally much higher than one would expect from weaning associated stress $[24,41,46]$ and they do not follow the same pattern of expression as cortisol. The former could be an effect of sedation during venipuncture (piglets in the current study were conscious during venipuncture whereas piglets in the mentioned studies were sedated) and the latter may be related to a difference in timing of release from sites of origin. Furthermore, the reason for the significant decrease in CRH at $1 \mathrm{~d}$ after weaning for the IS pigs is also not known and since this treatment effect was not reflected in the post-weaning injury scores or other blood parameters, then it may be suggested that further research is required to examine the potential adaptive advantage gradual weaning may have on GIT morphology and function around the time of weaning.

Similar to other IS studies, the IS piglets in the current study ate double the amount of creep feed compared to the CW group before weaning. Nabuurs et al. [47] reported that piglets offered creep feed during lactation in combination with IS had an improved villous height and net absorption after weaning, suggesting that IS piglets were better adapted to weaning as a result of higher creep ADFI during lactation. The results of the current study could illustrate a similar effect as evidenced by the IS group tending to have faster growth than the $\mathrm{CW}$ group from $3 \mathrm{~d}$ to $7 \mathrm{~d}$ after weaning despite having similar ADFI during this time. This is further supported by the positive correlation between ADFI during lactation and ADG from $3 \mathrm{~d}$ to $7 \mathrm{~d}$ post-weaning, suggesting that litters that ate more during lactation were more likely to have faster growth rates between $3 \mathrm{~d}$ and $7 \mathrm{~d}$ post-weaning. 


\section{Conclusions}

Apart from a transient peak in cortisol at the start of IS, piglets subjected to IS did not display neuroendocrine changes suggestive of a chronic stress response during the separation period ( $8 \mathrm{~h}$ daily separation for $7 \mathrm{~d}$ before weaning) and more importantly, there appeared to be no overall biological cost to these animals during this time as measured by performance, immune and inflammatory parameters. The event of weaning still caused a decrease in growth rate and an increase in N:L ratios in both groups. However, there was a tendency for IS pigs to grow faster than the $\mathrm{CW}$ pigs during the immediate post-weaning period. There were no differences in injury scores between the two groups after weaning.

Acknowledgments: Appreciation is extended to the Cooperative Research Centre for High Integrity Australian Pork for funding and provision of a postgraduate scholarship to the first author. The technical assistance of Josephine Mansfield is also gratefully acknowledged.

Author Contributions: Diana L. Turpin conducted the experiment, processed the results and data, and wrote the research results and their discussion. Tai-Yuan Chen and David Lines assisted with the experiment. Pieter Langendijk and John R. Pluske assisted with and supervised the experiment.

Conflicts of Interest: The authors declare no conflict of interest.

\section{Abbreviations}

The following abbreviations are used in this manuscript:

$\mathrm{CRH} \quad$ corticotrophin releasing hormone

CW corticotrophin releasing hormone

IS Intermittent suckling

\section{References}

1. Gerritsen, R.; Soede, N.; Langendijk, P.; Hazeleger, W.; Kemp, B. The intermittent suckling regimen in pigs: Consequences for reproductive performance of sows. Reprod. Domest. Anim. 2008, 43, 29-35. [CrossRef] [PubMed]

2. Downing, J.; Brock, D.; Smits, R.; Giles, L. Induction of Oestrus in Lactation Results in Normal Mating and Farrowing Performance, Manipulating Pig Production XII, Cairns, Queensland, Australia, 2009; Van Barneveld, R., Ed.; Australasian Pig Science Association (Inc.): Cairns, Australia, 2009; p. 144.

3. Pluske, J.R.; Hampson, D.J.; Williams, I.H. Factors influencing the structure and function of the small intestine in the weaned pig: A review. Livest. Prod. Sci. 1997, 51, 215-236. [CrossRef]

4. Bøe, K. The process of weaning in pigs: When the sow decides. Appl. Anim. Behav. Sci. 1991, 30, 47-59. [CrossRef]

5. Weary, D.M.; Pajor, E.A.; Bonenfant, M.; Fraser, D.; Kramer, D.L. Alternative housing for sows and litters: Part 4. Effects of sow-controlled housing combined with a communal piglet area on pre-and post-weaning behaviour and performance. Appl. Anim. Behav. Sci. 2002, 76, 279-290. [CrossRef]

6. Kuller, W.; Soede, N.; van Beers-Schreurs, H.; Langendijk, P.; Taverne, M.; Verheijden, J.; Kemp, B. Intermittent suckling: Effects on piglet and sow performance before and after weaning. J. Anim. Sci. 2004, 82, 405-413. [PubMed]

7. Kuller, W.; Soede, N.; van Beers-Schreurs, H.; Langendijk, P.; Taverne, M.; Kemp, B.; Verheijden, J. Effects of intermittent suckling and creep feed intake on pig performance from birth to slaughter. J. Anim. Sci. 2007, 85, 1295-1301. [CrossRef] [PubMed]

8. Berkeveld, M.; Langendijk, P.; van Beers-Schreurs, H.M.; Koets, A.P.; Taverne, M.A.; Verheijden, J.H. Postweaning growth check in pigs is markedly reduced by intermittent suckling and extended lactation. J. Anim. Sci. 2007, 85, 258-266. [CrossRef] [PubMed]

9. Berkeveld, M.; Langendijk, P.; Soede, N.M.; Kemp, B.; Taverne, M.A.; Verheijden, J.H.; Kuijken, N.; Koets, A.P. Improving adaptation to weaning: Effect of intermittent suckling regimens on piglet feed intake, growth, and gut characteristics. J. Anim. Sci. 2009, 87, 3156-3166. [CrossRef] [PubMed] 
10. Dybkjær, L. The identification of behavioural indicators of "stress" in early weaned piglets. Appl. Anim. Behav. Sci. 1992, 35, 135-147. [CrossRef]

11. Mormède, P.; Andanson, S.; Aupérin, B.; Beerda, B.; Guémené, D.; Malmkvist, J.; Manteca, X.; Manteuffel, G.; Prunet, P.; van Reenen, C.G.; et al. Exploration of the hypothalamic-pituitary-adrenal function as a tool to evaluate animal welfare. Physiol. Behav. 2007, 92, 317-339. [CrossRef] [PubMed]

12. Widowski, T.; Cottrell, T.; Dewey, C.; Friendship, R. Observations of piglet-directed behavior patterns and skin lesions in eleven commercial swine herds. J. Swine Health Prod. 2003, 11, 181-185.

13. Stevenson, J.S.; Davis, D.L. Influence of reduced litter size and daily litter separation on fertility of sows at 2 to 5 weeks postpartum. J. Anim. Sci. 1984, 59, 284-293. [PubMed]

14. Newton, E.A.; Stevenson, J.S.; Davis, D.L. Influence of duration of litter separation and boar exposure on estrous expression of sows during and after lactation. J. Anim. Sci. 1987, 65, 1500-1506. [PubMed]

15. Moberg, G. Biological response to stress: Implications for animal welfare. In The Biology of Animal Stress: Basic Principles and Implications for Animal Welfare; CABI Publishing: Wallingford, UK, 2000; pp. 1-21.

16. Hemsworth, P.; Mellor, D.; Cronin, G.; Tilbrook, A. Scientific assessment of animal welfare. N. Z. Vet. J. 2015, 63, 24-30. [CrossRef] [PubMed]

17. Klemcke, H.G.; Pond, W.G. Porcine adrenal adrenocorticotropic hormone receptors: Characterization, changes during neonatal development, and response to a stressor. Endocrinology 1991, 128, 2476-2488. [CrossRef] [PubMed]

18. Kanitz, E.; Tuchscherer, M.; Puppe, B.; Tuchscherer, A.; Stabenow, B. Consequences of repeated early isolation in domestic piglets (Sus scrofa) on their behavioural, neuroendocrine, and immunological responses. Brain Behav. Immun. 2004, 18, 35-45. [CrossRef]

19. McCormick, C.M.; Kehoe, P.; Kovacs, S. Corticosterone release in response to repeated, short episodes of neonatal isolation: Evidence of sensitization. Int. J. Dev. Neurosci. 1998, 16, 175-185. [CrossRef]

20. Berkeveld, M.; Langendijk, P.; Bolhuis, J.E.; Koets, A.P.; Verheijden, J.H.; Taverne, M.A. Intermittent suckling during an extended lactation period: Effects on piglet behavior. J. Anim. Sci. 2007, 85, 3415-3424. [CrossRef] [PubMed]

21. Van der Meulen, J.; Koopmans, S.; Dekker, R.; Hoogendoorn, A. Increasing weaning age of piglets from 4 to 7 weeks reduces stress, increases post-weaning feed intake but does not improve intestinal functionality. Animal 2010, 4, 1653-1661. [CrossRef] [PubMed]

22. Hay, M.; Orgeur, P.; Lévy, F.; Le Dividich, J.; Concordet, D.; Nowak, R.; Schaal, B.S.; Mormède, P. Neuroendocrine consequences of very early weaning in swine. Physiol. Behav. 2001, 72, 263-269. [CrossRef]

23. Mason, S.P.; Jarvis, S.; Lawrence, A.B. Individual differences in responses of piglets to weaning at different ages. Appl. Anim. Behav. Sci. 2003, 80, 117-132. [CrossRef]

24. Moeser, A.J.; Vander Klok, C.; Ryan, K.A.; Wooten, J.G.; Little, D.; Cook, V.L.; Blikslager, A.T. Stress signaling pathways activated by weaning mediate intestinal dysfunction in the pig. Am. J. Physiol. Gastrointest. Liver Physiol. 2007, 292, G173-G181. [CrossRef] [PubMed]

25. Worsaae, H.; Schmidt, M. Plasma cortisol and behaviour in early weaned piglets. Acta Vet. Scand. 1980, 21, 640-657. [PubMed]

26. Worobec, E.K.; Duncan, I.J.H.; Widowski, T.M. The effects of weaning at 7, 14 and 28 days on piglet behaviour. Appl. Anim. Behav. Sci. 1999, 62, 173-182. [CrossRef]

27. Sales, N.; Collins, D.; Collins, A.; McKenna, T.; Bauer, M.; Parke, C.; Hermesch, S. Porcine haptoglobin levels measured at 7-14 days after weaning were independent of age, weight or gender. Anim. Prod. Sci. 2015, 55, 1457-1457.

28. Piñeiro, C.; Piñeiro, M.; Morales, J.; Carpintero, R.; Campbell, F.; Eckersall, P.; Toussaint, M.; Alava, M.; Lampreave, F. Pig acute-phase protein levels after stress induced by changes in the pattern of food administration. Animal 2007, 1, 133-139. [CrossRef] [PubMed]

29. Eckersall, P.; Bell, R. Acute phase proteins: Biomarkers of infection and inflammation in veterinary medicine. Vet. J. 2010, 185, 23-27. [CrossRef] [PubMed]

30. Hicks, T.A.; McGlone, J.J.; Whisnant, C.S.; Kattesh, H.G.; Norman, R.L. Behavioral, endocrine, immune, and performance measures for pigs exposed to acute stress. J. Anim. Sci. 1998, 76, 474-483. [PubMed]

31. Sorensen, N.; Tegtmeier, C.; Andresen, L.O.; Pineiro, M.; Toussaint, M.; Campbell, F.; Lampreave, F.; Heegaard, P.M. The porcine acute phase protein response to acute clinical and subclinical experimental infection with streptococcus suis. Vet. Immunol. Immunopathol. 2006, 113, 157-168. [CrossRef] [PubMed] 
32. Heegaard, P.M.; Klausen, J.; Nielsen, J.P.; González-Ramón, N.; Piñeiro, M.; Lampreave, F.; Alava, M.A. The porcine acute phase response to infection with Actinobacillus pleuropneumoniae. Haptoglobin, c-reactive protein, major acute phase protein and serum amyloid a protein are sensitive indicators of infection. Compar. Biochem. Physiol. Part B: Biochem. Mol. Biol. 1998, 119, 365-373. [CrossRef]

33. Jungersen, G.; Jensen, L.; Riber, U.; Heegaard, P.M.; Petersen, E.; Poulsen, J.; Bille-Hansen, V.; Lind, P. Pathogenicity of selected Toxoplasma gondii isolates in young pigs. Int. J. Parasitol. 1999, 29, 1307-1319. [CrossRef]

34. Sauerwein, H.; Schmitz, S.; Hiss, S. The acute phase protein haptoglobin and its relation to oxidative status in piglets undergoing weaning-induced stress. Redox Rep. 2005, 10, 295-302. [CrossRef] [PubMed]

35. Vente-Spreeuwenberg, M.; Verdonk, J.; Verstegen, M.; Beynen, A. Villus height and gut development in weaned piglets receiving diets containing either glucose, lactose or starch. Br. J. Nutr. 2003, 90, 907-913. [CrossRef] [PubMed]

36. Piñeiro, C.; Piñeiro, M.; Morales, J.; Andrés, M.; Lorenzo, E.; del Pozo, M.; Alava, M.A.; Lampreave, F. Pig-map and haptoglobin concentration reference values in swine from commercial farms. Vet. J. 2009, 179, 78-84. [CrossRef] [PubMed]

37. Petersen, H.; Nielsen, J.; Jensen, A.; Heegaard, P.M. Evaluation of an enzyme-linked immunosorbent assay for determination of porcine haptoglobin. J. Vet. Med. 2001, 48, 513-523. [CrossRef]

38. Blecha, F.; Pollman, D.; Nichols, D. Weaning pigs at an early age decreases cellular immunity. J. Anim. Sci. 1983, 56, 396-400. [PubMed]

39. Blecha, F.; Pollmann, D.; Nichols, D. Immunologic reactions of pigs regrouped at or near weaning. Am. J. Vet. Res. 1985, 46, 1934-1937. [PubMed]

40. Pié, S.; Lalles, J.; Blazy, F.; Laffitte, J.; Sève, B.; Oswald, I. Weaning is associated with an upregulation of expression of inflammatory cytokines in the intestine of piglets. J. Nutr. 2004, 134, 641-647. [PubMed]

41. Moeser, A.J.; Ryan, K.A.; Nighot, P.K.; Blikslager, A.T. Gastrointestinal dysfunction induced by early weaning is attenuated by delayed weaning and mast cell blockade in pigs. Am. J. Physiol. Gastrointest. Liver Physiol. 2007, 293, G413-G421. [CrossRef] [PubMed]

42. Puppe, B.; Tuchscherer, M.; Tuchscherer, A. The effect of housing conditions and social environment immediately after weaning on the agonistic behaviour, neutrophil/lymphocyte ratio, and plasma glucose level in pigs. Livest. Prod. Sci. 1997, 48, 157-164. [CrossRef]

43. Metz, J.H.M.; Gonyou, H.W. Effect of age and housing conditions on the behavioural and haemolytic reaction of piglets to weaning. Appl. Anim. Behav. Sci. 1990, 27, 299-309. [CrossRef]

44. Kiliaan, A.J.; Saunders, P.R.; Bijlsma, P.B.; Berin, M.C.; Taminiau, J.A.; Groot, J.A.; Perdue, M.H. Stress stimulates transepithelial macromolecular uptake in rat jejunum. Am. J. Physiol. Gastrointest. Liver Physiol. 1998, 275, G1037-G1044.

45. Meddings, J.B.; Swain, M. Environmental stress-induced gastrointestinal permeability is mediated by endogenous glucocorticoids in the rat. Gastroenterology 2000, 119, 1019-1028. [CrossRef] [PubMed]

46. Smith, F.; Clark, J.E.; Overman, B.L.; Tozel, C.C.; Huang, J.H.; Rivier, J.E.; Blisklager, A.T.; Moeser, A.J. Early weaning stress impairs development of mucosal barrier function in the porcine intestine. Am. J. Physiol. Gastrointest. Liver Physiol. 2010, 298, G352-G363. [CrossRef] [PubMed]

47. Nabuurs, M.; Hoogendoorn, A.; Van Zijderveld-Van Bemmel, A. Effect of supplementary feeding during the sucking period on net absorption from the small intestine of weaned pigs. Res. Vet. Sci. 1996, 61, 72-77. [CrossRef]

(C) 2016 by the authors; licensee MDPI, Basel, Switzerland. This article is an open access article distributed under the terms and conditions of the Creative Commons by Attribution (CC-BY) license (http://creativecommons.org/licenses/by/4.0/). 